Journal of Thermal Engineering, Vol. 6, No. 5, pp. 786-801, October 2020

Yildiz Technical University Press, Istanbul, Turkey

\title{
THERMAL PERFORMANCE ANALYSIS OF GLAZED AND UNGLAZED RECEIVER OF SCHEFFLER DISH
}

\author{
Dnyaneshwar Malwad ${ }^{1, *}$, Vinod Tungikar $^{1}$
}

\begin{abstract}
The impact of reradiation and convection losses from the receiver is substantial on the performance of solar parabolic dish concentrator. In this paper, an experimental and theoretical study to compare the performance of the glazed and unglazed receiver of Scheffler dish for direct steam generation is presented. Tempered glass cover is provided on aperture to reduce the reradiation and convection losses from the receiver. Improvement in the efficiency of the Scheffler dish is found due to suppressed heat losses from the receiver front surface. Overall heat loss coefficient, useful energy transfer rate to water, steam flow rate, and efficiency of the system with and without glass cover on the receiver are evaluated and compared. The average solar beam intensity during experimentation was 569 $\mathrm{W} / \mathrm{m}^{2}$ and $600 \mathrm{~W} / \mathrm{m}^{2}$ with the glazed and unglazed receiver respectively. The average temperature at the receiver with glazing is recorded as $425^{\circ} \mathrm{C}$, even at low solar beam intensity in comparison with the unglazed receiver. Overall heat loss coefficient at the front surface of the receiver is reduced to $6.04 \mathrm{~W} / \mathrm{m}^{2} \mathrm{~K}$. It has been observed that the Scheffler dish with a glazed receiver achieves thermal performance above $50.00 \%$ within the solar beam intensity range of $600-650 \mathrm{~W} / \mathrm{m}^{2}$. The enhancement of $8.74 \%$ in the average thermal efficiency, with glass cover on the receiver is achieved.
\end{abstract}

Keywords: Scheffler Dish, Glazed Receiver, Direct Steam Generation, Thermal Efficiency

\section{INTRODUCTION}

Solar energy is an encouraging source of renewable energy. Development in solar energy harvesting technologies plays an important role in the replacement of fossil fuels for electricity generation and heat applications. Significant progress has been made in solar reflector for the utilization of concentrated solar energy; it is a powerful way to thermal energy. Concentrated solar power (CSP) technology is gaining attention due to its medium and hightemperature applications in industrial process heat, institutional and community cooking [1]. CSP has been proven it is widespread technology that is not so difficult to built and use. In the CSP system, reflected solar radiations from reflector are concentrated at the receiver to heat up a heat transfer fluid circulating through the receiver. Depending upon the temperature requirement line focus or point focus solar concentrators are used. Thermal performance of the CSP system is a key element for cost management in the operation of the system [2]. Geometrical and optical parameter of solar concentrator also influences the efficiency of the system [3]. Researchers have proposed the use of nanofluids to improve the thermal efficiency of solar collectors [4,5]. Further efforts are needed to study the reliability of using nanofluids in solar collectors from an environmental and economic perspective [6]. Introducing a phase change material (PCM) inside a receiver can increase the total weight of the receiver, which is not conducive to commercial purposes.

Many studies have shown the effectiveness of glass cover on the horizontal receiver pipe of parabolic trough collector and compound parabolic concentrator (CPC) [7,8]. CPC system consists of a pumping system for the recirculation of heat transfer fluid through the receiver. More space is required for the CPC plant than a parabolic dish. CPC system is less efficient for small-scale thermal applications. Thus, there is a need for testing efficient, low cost, and user-friendly CSP systems. Among the CSP systems, Scheffler dish has been used for many thermal

This paper was recommended for publication in revised form by Regional Editor Jaap Hoffman

${ }^{1}$ Department of Production Engineering, SGGS Institute of Engineering and Technology, Nanded (MS), India

*E-mail address: dsmalwad@gmail.com, 2017ppe601@sggs.ac.in

Orcidid: 0000-0002-7161-7564, 0000-0001-7207-3071

Manuscript Received 11 October 2019, Accepted 8 February 2020 
applications. Scheffler concentrators are used for distillation, cremation, coffee making, syrup production, oil extraction, food cooking, and electricity generation [9]. The selection of suitable receiver geometry is difficult due to seasonal variation in the size of the elliptical focal image formed at the receiver [10]. Some researchers have proposed cavity receivers for solar parabolic dish type concentrator [11,12]. However, small receiver size cannot intercept all reflected radiation and large receiver size increases heat losses. High-temperature transparent glass cover on the receiver allows selecting enough large receiver size with minimized heat losses. Glazing over the receiver is an easy and efficient method to enhance the performance of the Scheffler solar concentrator. Trushevskii and Mitina [13] carried out an experimental study to analyze the effect of vacuum and double glazing on solar collector plate temperature. Resistance to heat losses due to vacuum is observed to be $59.5 \%$. Providing transparent glass cover on absorber eliminates the effect of varying convective heat transfer coefficient of wind on receiver temperature. Bisen, Dass, and Jain [14] analyzed the effect of ambient temperature, absorber plate temperature, and wind speed on the heat loss coefficient. An analytical result shows that losses increase with an increase in plate temperature and heat transfer coefficient of wind. Dafle and Shinde [15] evaluated the performance of Scheffler reflector for water heating and steam generation. The author reported heat loss from Scheffler receiver increases as solar radiation intensity and wind-heat transfer coefficient increases. Uhlig et al. [16] presented two different methods to increase the efficiency of the cavity receiver in a concentrated solar power system. Transparent covering to the receiver showed significant improvement in performance instead of optimizing the size of the receiver. Jadhav et al. [17] observed fluctuations in efficiency with an unglazed receiver of the compound parabolic concentrator. Enhanced performance with stable efficiency is achieved when rays are concentrated on the glazed receiver. Mbodji and Hajji [18] tested a parabolic dish for solar cooking. The author achieved a $140^{\circ} \mathrm{C}$ temperature of synthetic oil with a glazed receiver against $125^{\circ} \mathrm{C}$ without glazing. Chandrashekara and Yadav $[19,20]$ experimentally studied the effect of exfoliated graphite coating on a receiver with Scheffler concentrator. Exfoliated graphite coating improves the efficiency of the desalination system by $9 \%$ and $13 \%$ with sensible heat and latent heat storage system respectively. Abedini Najafabadi and Ozalp [21] presented a variable aperture size mechanism to control the temperature at the solar receiver. Reflected solar beam radiation entry in the cavity is regulated by a variable aperture mechanism. The effect of variation in solar intensity is compensated by adjusting the receiver aperture. Stefanovic et al. [22] investigated the effect of different parameters on the performance of a solar dish collector. Maximum thermal efficiency 49.83\% achieved with flow rate $314.6 \mathrm{~L} / \mathrm{h}$. Nene et al. [23] compared the effect of wind flow on performance of cylindrical and conical receiver of Scheffler dish. Heat losses from the cylindrical receiver are more than a conical shape receiver. The tilt angle of $45^{\circ}$ is found to be good for a conical receiver to reduce heat loss due to convection. Ganesh Kumar et al. [24] suggested Polysulfone glazing material for the solar thermal system. Dong Li et al. [25] examined the thermal behavior of the double glazing structure filled with PCM and analyzed the effect of PCM's thermophysical parameters on the system thermal performance and found that the increased latent heat of PCM and controlled melting temperature improve the thermal efficiency of the double glazed unit. A. K. Hussein and A. A. Walunj [26] focused on the fundamental aspects of nanofluid in direct absorption solar collectors and concluded that environmental and economical reliability are challenges in the application of nanotechnology to direct absorption solar collectors. Arun Kumar and S.K. Shukla [27] reported a 4.35\% increase in receiver temperature and enhancement in heat transfer coefficient with dual glass cover helical coil receiver compared to horizontal tube receiver. According to S. Bopche and S. Kumar [28] glazing thickness, $4 \mathrm{~mm}$ gives better transmittance and reduces losses due to convective and radiative mode heat transfer. In the work of O. Lopez et al. [29] losses from the receiver due to increases aperture area of the receiver are reduced by glazing the cavity aperture with a glass cover. Cavity receiver with glass cover found to be efficient suppressing convective and radiative losses.

Literature on the nature of heat losses from the receiver and different alternatives used to improve the performance of solar collectors reviewed. Researchers have focused on receiver size and shape, absorber coating, glass glazing, and use of nanofluids as phase change material to utilize the maximum energy received from the concentrator. Recent studies have shown that glass cover on the receiver plays an important role in the performance enhancement of the CSP system however; the use of transparent glazing has been made for only low-temperature systems. 
In the present work, we have evaluated the performance of Scheffler dish with a hollow convex receiver in glazed and unglazed conditions. Receiver temperature, overall heat loss coefficient, useful power available for heat transfer fluid and efficiency of the system is compared for direct steam generation. Glazing glass, which acts as transparent insulation for Scheffler dish receiver, is tested above $500^{\circ} \mathrm{C}$ to justify the importance of transparent glazing for high-temperature point focus solar thermal systems.

\section{SYSTEM DESCRIPTION AND EXPERIMENTAL PROCEDURE}

The methodology consists of a brief description of Scheffler reflector and receiver. The system is designed and developed to supply the steam for turmeric blanching.

\section{Reflector}

Scheffler concentrator is a section of paraboloid used to direct incident solar rays to a fixed-point receiver. The elliptical shape parabolic frame is suspended on rotating pipe support. The frame consists of 20 crossbars on which solar-grade mirror pieces of size $22 \mathrm{~cm} \times 22 \mathrm{~cm}$ are fixed. Reflected solar beam radiations concentrate on the receiver placed on the axis of rotation of the dish. A dual-axis tracking system is used to concentrate maximum solar radiation at the receiver. Relay controlled DC motor is used for continuous rotation of dish about a polar axis to track Sun position. Seasonal North-South tracking is done manually by adjusting the telescopic bars. Seasonal tracking needs adjustment after every 3-4 days [30].

\section{Receiver}

A hollow convex receiver made of cast iron is mounted at a focal point. The receiver is sized to have 18 liters of water storage capacity. The receiver front surface is coated with anti-reflective black paint and all other surfaces are perfectly insulated by rock wool of $50 \mathrm{~mm}$ thickness. The receiver absorbs energy from reflected beam radiation and transfers it to water in the form of heat. A thermally insulated cylindrical tank of 30 liters capacity is provided above the receiver. The tank is connected with the receiver by piping for continuous recirculation of water through the receiver. Low-temperature water in the tank sink to the receiver cavity form bottom and gets heated due to high temperature at the receiver. Lower density water from the receiver comes up in the header tank through interconnected piping. Continuous recirculation of water occurs due to lower relative density (Thermosyphon principle) [31]. Steam is separated from the water-vapor mixture and collected from the exit pipe provided at top of the tank. The tank serves a dual purpose of water storage and steam separator. Glazed and unglazed receivers are shown in Figure 1. A thermally insulated cavity is provided to maintain a sufficient gap between the receiver surface and glazing glass. The cavity has an inner diameter $600 \mathrm{~mm}$, thickness $50 \mathrm{~mm}$ and length $250 \mathrm{~mm}$. Reflector and receiver system parameters are given in Table 1.

Saint-Gobain made tempered glass is mounted at the front of the cavity to reduce losses due to radiation and convection. Toughened glass is four to ten times stronger than annealed glass [32]. Toughening does not change the solar radiation transmission properties of the glass. The toughened glass used in the current study has higher thermal strength and can withstand a thermal shock resistance up to $700^{\circ} \mathrm{C}$. The life of the toughened glass depends on the temper quality degradation rate. Mount hooks are welded to the front metallic ring of the cavity structure to support and hold the glass. The small gap between cavity surface and glass is filled with high-temperature silicone sealant and insulation is provided on it.

Table 1. System parameters

\begin{tabular}{|c|l|l|}
\hline Sr. No. & \multicolumn{1}{|c|}{ Parameter } & Value (unit) \\
\hline 1 & Effective surface area of Scheffler concentrator & $15 \mathrm{~m}^{2}$ \\
\hline 2 & Focal length of the Scheffler concentrator & $2.5 \mathrm{~m}$ \\
\hline 2 & Irradiation Concentration Ratio & 116.13 \\
\hline 3 & Optical efficiency of the concentrator & $74 \%$ \\
\hline
\end{tabular}




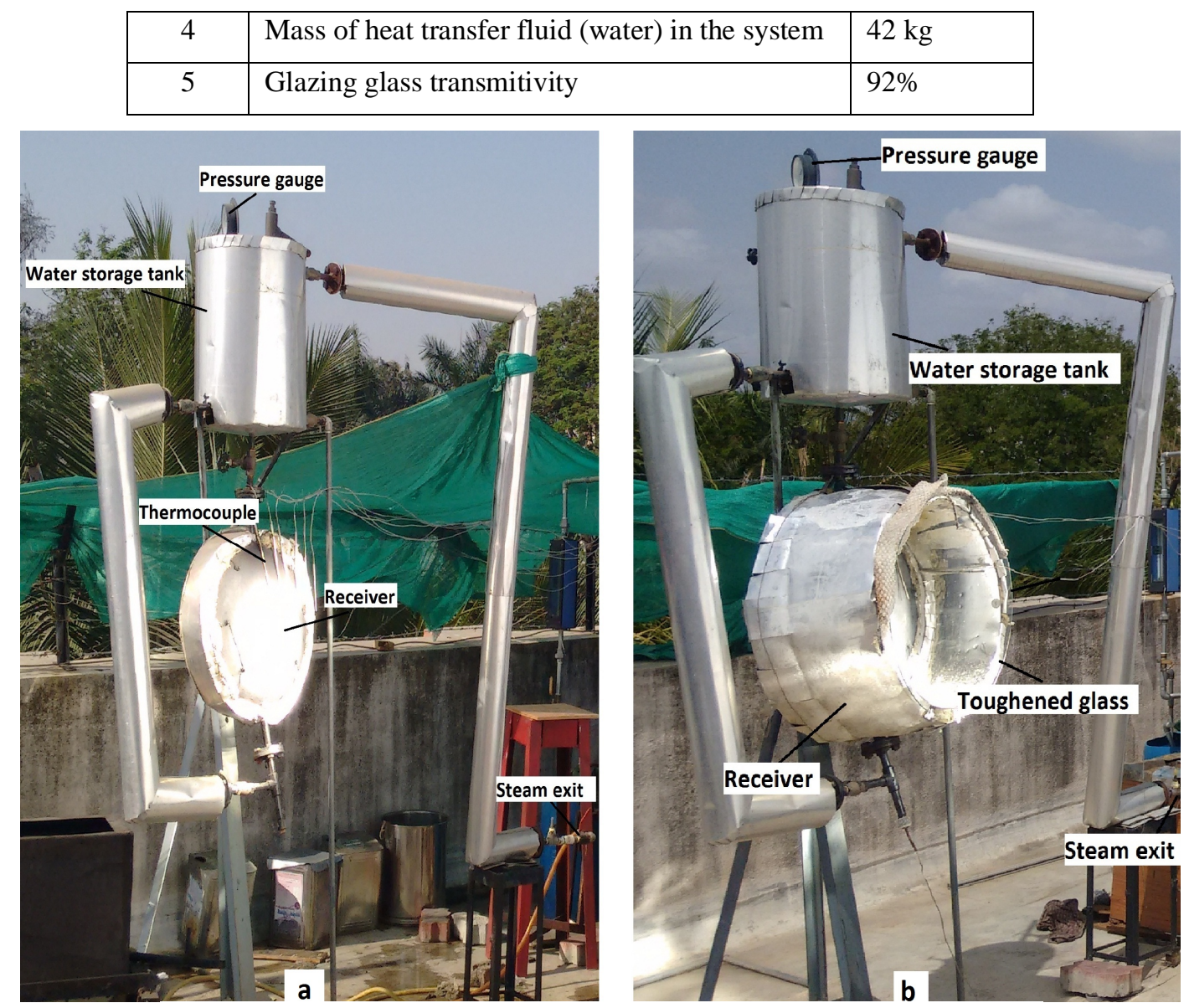

Figure 1. Photograph of (a) Unglazed receiver (b) Glazed receiver

\section{Experimental setup}

Experiments were conducted from the mid of April 2019 to the beginning of June 2019 at Nanded (MS), India (latitude 19.1114 North, longitude 77.2945 East). The schematic of the experimental setup is shown in Figure 2. The parameters considered during the experiment are beam radiation, ambient temperature, wind speed, and receiver temperature, which are recorded continuously every 15 minutes. All the experiments were conducted between 9:00 hrs to 17:00 hrs because of solar intensity during this period is enough to produce steam. The intensity of solar radiation is measured using irradiation meter, which is mounted on the reflector frame of Scheffler dish. Ambient temperature and steam temperature are monitored with pt100 RTD. Thermocouples are placed on the receiver to measure receiver surface temperature. Wind speed is measured with an anemometer. A detail about the instrumentation used is given in Table 2. The direct steam condensation method is used to determine the steam flow rate. Steam is allowed to pass in a vessel, which is surrounded, by another large vessel to the provided water jacket. Continuous pouring of $15^{\circ} \mathrm{C}$ cold water and draining $70^{\circ} \mathrm{C}$ hot water increases the steam condensation rate.

Table 2. List of measuring instruments

\begin{tabular}{|c|l|l|l|}
\hline Sr. No. & Measuring Instrument & Measurement Range & Accuracy \\
\hline 1 & Thermocouple k-type & $0-800^{\circ} \mathrm{C}$ & $\pm 1^{\circ} \mathrm{C}$ \\
\hline 2 & Pressure gauge & $0-69$ Pascal & \pm 1 Pascal \\
\hline 3 & Irradiance meter & $100-1250 \mathrm{~W} / \mathrm{m}^{2}$ & $\pm 1 \mathrm{~W} / \mathrm{m}^{2}$ \\
\hline
\end{tabular}


Journal of Thermal Engineering, Research Article, Vol. 6, No. 5, pp. 786-801, Octo

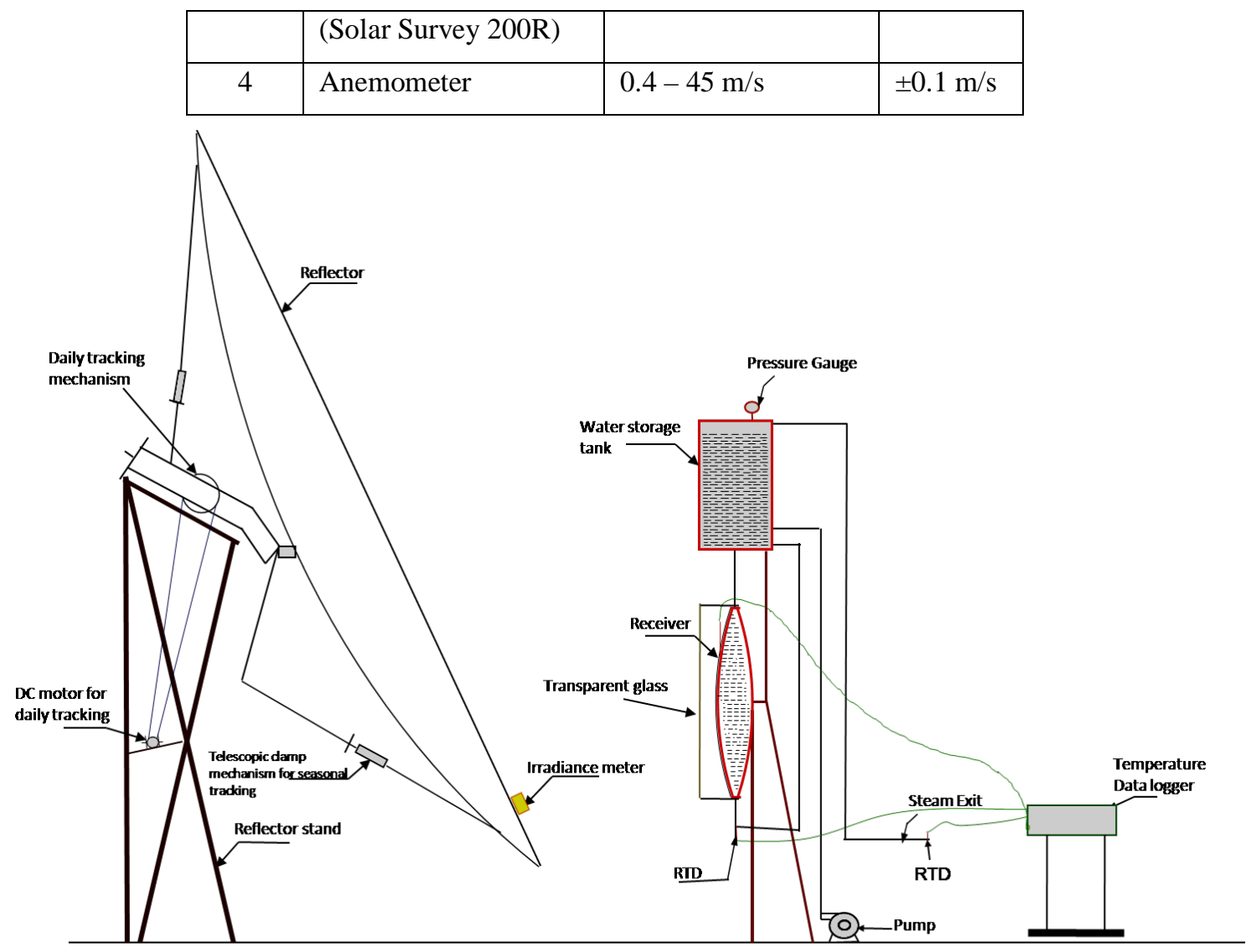

Figure 2. Schematic of experimental setup

\section{MATHEMATICAL MODELING}

\section{Solar energy utilization}

Direct solar radiation incident on reflecting surface of Scheffler concentrator is a primary source of energy. Power available at Scheffler concentrator is given as:

$$
Q_{c}=A_{c} I_{b}
$$

Daily variation in the declination angle is considered for aperture area Ac (m2) determination. It is calculated from the following equation [33]:

$$
A_{c}=A_{s} \cos \left(43.23 \pm \frac{\delta}{2}\right)
$$

Declination angle is positive (+) for the southern hemisphere and negative $(-)$ for the northern hemisphere. Declination angle $\delta$ is determined from following equation [34]:

$$
\delta=23.45\left[2 \pi\left(\frac{284+n}{365}\right)\right]
$$

where $\mathrm{n}$ is the day of the year from 1 January. 
Power received by the receiver is given as:

$$
Q_{r}=\rho A_{c} I_{b}
$$

\section{Heat loss analysis}

Unglazed:

Total heat loss from the front surface of an unglazed receiver to the atmosphere is given as

$$
Q_{l, u n}=Q_{c o n, r-a}+Q_{r a d, r-a}
$$

The convective heat transfer rate from the receiver and to surrounding

$$
Q_{c o n, r-a}=h_{c o n} A_{r}\left(T_{r}-T_{a}\right)
$$

$\mathrm{h}_{\mathrm{c}}$ is calculated using the relation reported by [34]

$$
h_{\text {con }}=5.7+3.8 \mathrm{~V}
$$

Heat loss rate to the atmosphere due to radiation is given by [35]

where

$$
Q_{r a d, r-a}=A_{r} h_{r a d}\left(T_{r}-T_{a}\right)
$$

$$
h_{r a d}=\frac{\epsilon_{r} \sigma\left(T_{r}^{4}-T_{s k y}^{4}\right)}{\left(T_{r}-T_{a}\right)}
$$

Overall heat loss coefficient is calculated as

$$
\frac{1}{U_{l, u n}}=\frac{1}{h_{c o n}+h_{\text {rad }}}
$$

Glazed:

Total heat loss from glazed receiver to ambient is given as

$$
Q_{l, g l}=Q_{r-g}+Q_{g-a}
$$

Heat loss from receiver surface to the cavity is expressed as

$$
Q_{r-g}=\left(h_{c o n, r-g}+h_{r a d, r-g}\right) A_{r}\left(T_{r}-T_{g}\right)
$$

Natural convection is present in the cavity and convective heat transfer coefficient is given as [36]

$$
h_{c o n, r-g}=\frac{k N u}{L}
$$

Correlation for determination of Nusselt number is presented as [35] 
Journal of Thermal Engineering, Research Article, Vol. 6, No. 5, pp. 786-801, Octo

$$
N u=0.18\left(\frac{P r R a}{0.2+P r}\right)^{0.29}
$$

Air properties between receiver and glass are calculated as [14]

$$
\operatorname{Pr}=1.0602-0.602 \log T_{m}
$$

where

$$
T_{m}=\frac{T_{p}+T_{g}}{2}
$$

Rayleigh number for enclosed space reported by [37] is

$$
R_{a}=\frac{9.8\left(T_{r}-T_{g}\right)(L)^{3} P r}{V^{2}\left(\frac{T_{r}+T_{g}}{2}\right)}
$$

Empirical relation for estimation of glass cover temperature is [38]

$$
T_{g}=T_{a}+r\left(T_{r}-T_{a}\right)
$$

where

$$
r=h_{w}^{-0.42}\left(0.621 \epsilon_{r}+\frac{T_{r}}{505}-0.27\right)
$$

Heat loss from glass surface to atmosphere is given as

$$
Q_{g-a}=\left(h_{c o n, g-a}+h_{r a d, g-a}\right) A_{g}\left(T_{g}-T_{a}\right)
$$

where $h_{c, g-a}$ and $h_{r, g-a}$ are calculated using relations in equation (7) and (9).

The overall heat loss coefficient is determined as

$$
\frac{1}{U_{l, g l}}=\frac{1}{\left(h_{c o n, r-g}+h_{r a d, r-g}\right)}+\frac{1}{\left(h_{c o n, g-a}+h_{r a d, g-a}\right)}
$$

\section{Energy analysis}

Heat energy available at the receiver is transferred for useful work and some part of it is lost.

$$
Q_{r}=Q_{u}+Q_{l}
$$

Rate of useful energy transferred to fluid is given

$$
Q_{u}=Q_{\text {sen }}+Q_{\text {lat }}
$$

Useful heat from the system is the energy required to raise the temperature of working fluid to its boiling point and then the energy required to vaporize it.

$$
Q_{\text {sen }}=m C_{p} \frac{\Delta T}{\Delta t}
$$


$m$ is the mass of the water; $C_{p}$ is the specific heat of water where $\frac{\Delta T}{\Delta t}$ is the rate of temperature rise with time.

$$
Q_{l a t}=\dot{m} h_{f g}
$$

The thermal efficiency of the Scheffler concentrator is the ratio of energy utilized for steam generation to the solar radiation received at the reflector.

\section{UNCERTAINTY ANALYSIS}

$$
\eta_{t h}=\frac{Q_{u}}{Q_{c}}
$$

Uncertainty during experimentation is inevitable after all corrections have been made in sources of errors. Uncertainty depends on the measurement condition, repeatability, and accuracy of the instrument. Error in each component of the measurement and measuring instrument induces uncertainty in the result. Receiver temperature, solar beam radiation, wind speed, mass of the condensate and thermal efficiency are uncertainty parameters in the current study. An average value of each independent variable was considered and uncertainty in the variable is determined from repeated observations. The uncertainty in the measurement of receiver temperature, solar beam radiation, wind speed, and condensate was estimated to be $6^{\circ} \mathrm{C}, 7 \mathrm{~W} / \mathrm{m}^{2}, 0.1 \mathrm{~m} / \mathrm{s}$ and $0.08 \mathrm{~kg}$ respectively. Percentage uncertainty of independent variables is presented in Table 3.

The uncertainty in the thermal efficiency was found to be a function of steam flow rate and solar beam radiation. The relative effect of primary measurement on the result is considered for calculation of uncertainty associated with the result. Uncertainty of measurement calculated using the following equation [39].

$$
w_{R}=\left[\left(\frac{\partial R}{\partial x_{1}} w_{1}\right)^{2}+\left(\frac{\partial R}{\partial x_{2}} w_{2}\right)^{2}+\cdots+\left(\frac{\partial R}{\partial x_{n}} w_{n}\right)^{2}\right]^{1 / 2}
$$

where $w_{1}, w_{2, \ldots .,}, w_{n}$ are the uncertainties in the independent variables and $w_{R}$ is uncertainty in results. The $\mathrm{R}$ is a given function of the independent variables $x_{1}, x_{2, \ldots . .,} x_{n}$. The uncertainty in the efficiency is $2.33 \%$, which is calculated from Equation. (27).

Table 3. Uncertainty of variables

\begin{tabular}{|c|l|c|}
\hline Sr. No. & \multicolumn{1}{|c|}{ Measurement } & Uncertainty \\
\hline 1 & Temperature & $1.43 \%$ \\
\hline 2 & Solar beam radiation & $1.24 \%$ \\
\hline 3 & Wind speed & $1.60 \%$ \\
\hline 4 & Condensate & $1.90 \%$ \\
\hline
\end{tabular}

\section{RESULT AND DISCUSSION}

A number of experiments were conducted from the month of April 2019 to June 2019 to record the different parameters and compare the performance of a system in glazed and unglazed conditions. Data obtained during clear sky conditions averaged to get a concrete outcome from the conducted experiments. The mean of five days of data for each case is considered for analysis and presenting the results. Variation of solar beam radiation with respect to time is shown in Figure 3. It can be seen that the maximum value of solar intensity is obtained between 11:45 to 12:45 hr in both glazed and unglazed condition. Average solar intensity $600 \mathrm{~W} / \mathrm{m} 2$ was recorded with glass cover on the receiver whereas with the unglazed receiver $569 \mathrm{~W} / \mathrm{m} 2$. The rapid decrease in solar beam intensity is observed to be after 15:00 hr. 


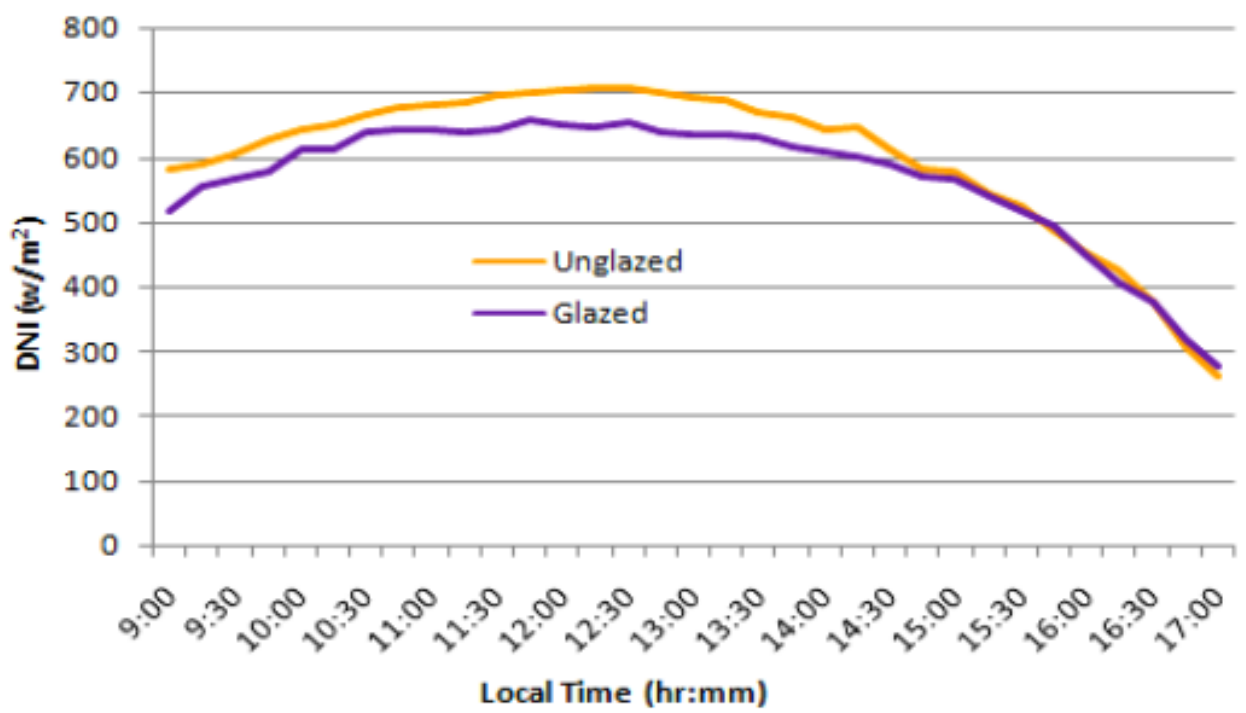

Figure 3. Variation of solar beam radiation

The convective heat transfer coefficient varies with wind speed over the receiver. Figure 4 shows the variation in wind speed and atmospheric temperature with time. Average wind speed $2.0 \mathrm{~m} / \mathrm{s}$ and $2.1 \mathrm{~m} / \mathrm{s}$ are recorded in glazed and unglazed conditions respectively. Atmospheric temperature increases from $34.7 \mathrm{oC}$ to $44.1 \mathrm{oC}$ during experimentation. Air temperature rapidly increases with an increase in solar intensity up to noon but a small variation in air temperature is observed after 13:30 hrs.

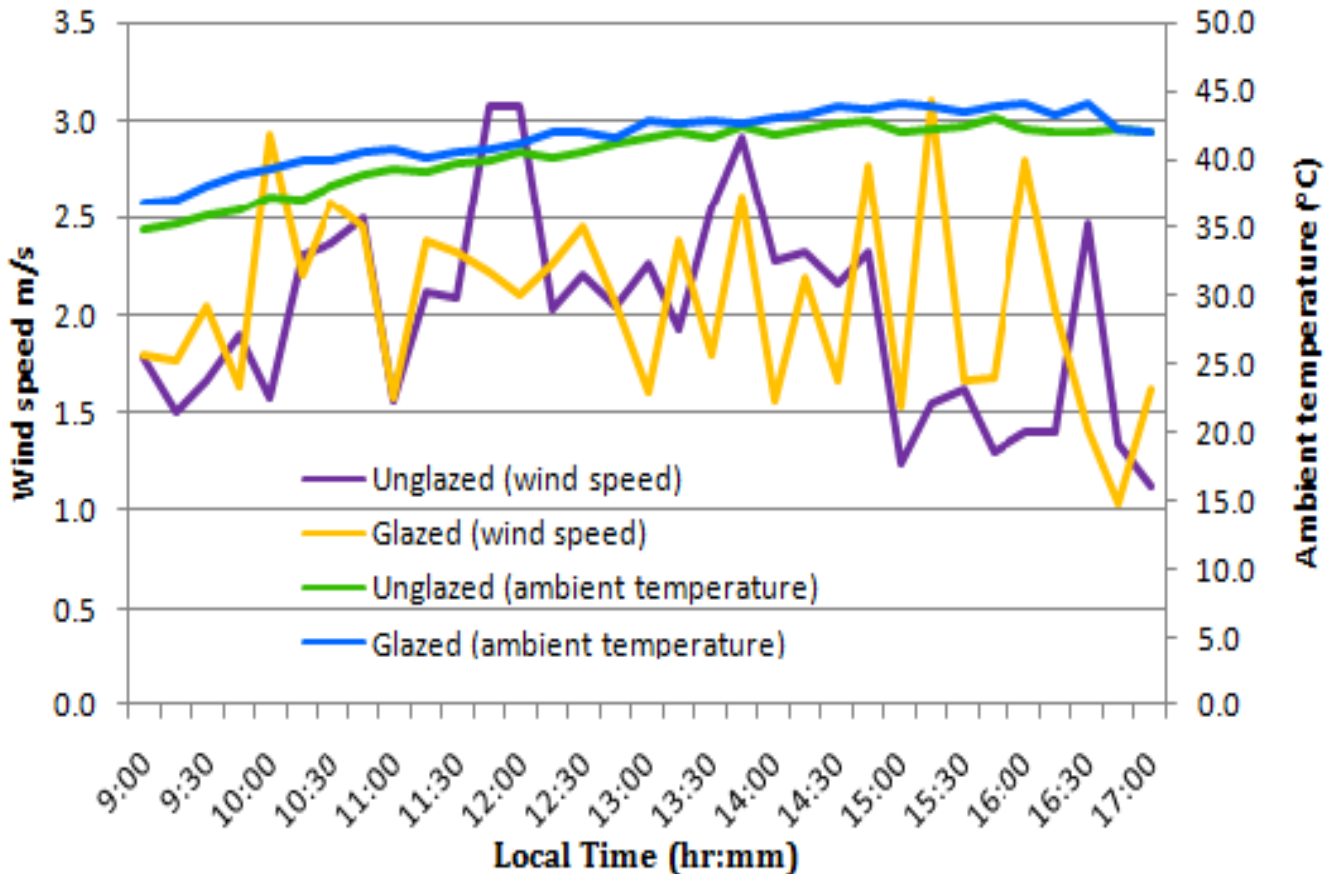

Figure 4. Wind speed and ambient temperature variation

The non-uniform temperature distribution is observed at the receiver. The temperature at the center of a receiver is higher and it decreases in the radial direction. Figure 5 depicts the variation in receiver mean temperature at the focus. When rays are concentrated receiver temperature suddenly rises above $300^{\circ} \mathrm{C}$. Undulation in glazed receiver temperature is perceived with variation in solar intensity. Inconstancy in unglazed receiver temperature is observed from beginning to end due to enhanced heat transfer from the receiver to the atmosphere. The maximum 
receiver temperature is achieved in between $12: 30$ to $13: 15 \mathrm{hr}$, with glazing $499^{\circ} \mathrm{C}$ and without glazing $550^{\circ} \mathrm{C}$. The temperature at focus drops below $200^{\circ} \mathrm{C}$ after $14: 30 \mathrm{hrs}$. due to the decrease in solar beam intensity. This will reduce the heat transfer rate to working fluid, which is at $100^{\circ} \mathrm{C}$ so rays concentrated after $17: 00 \mathrm{hrs}$ will not be utilized for steam generation.

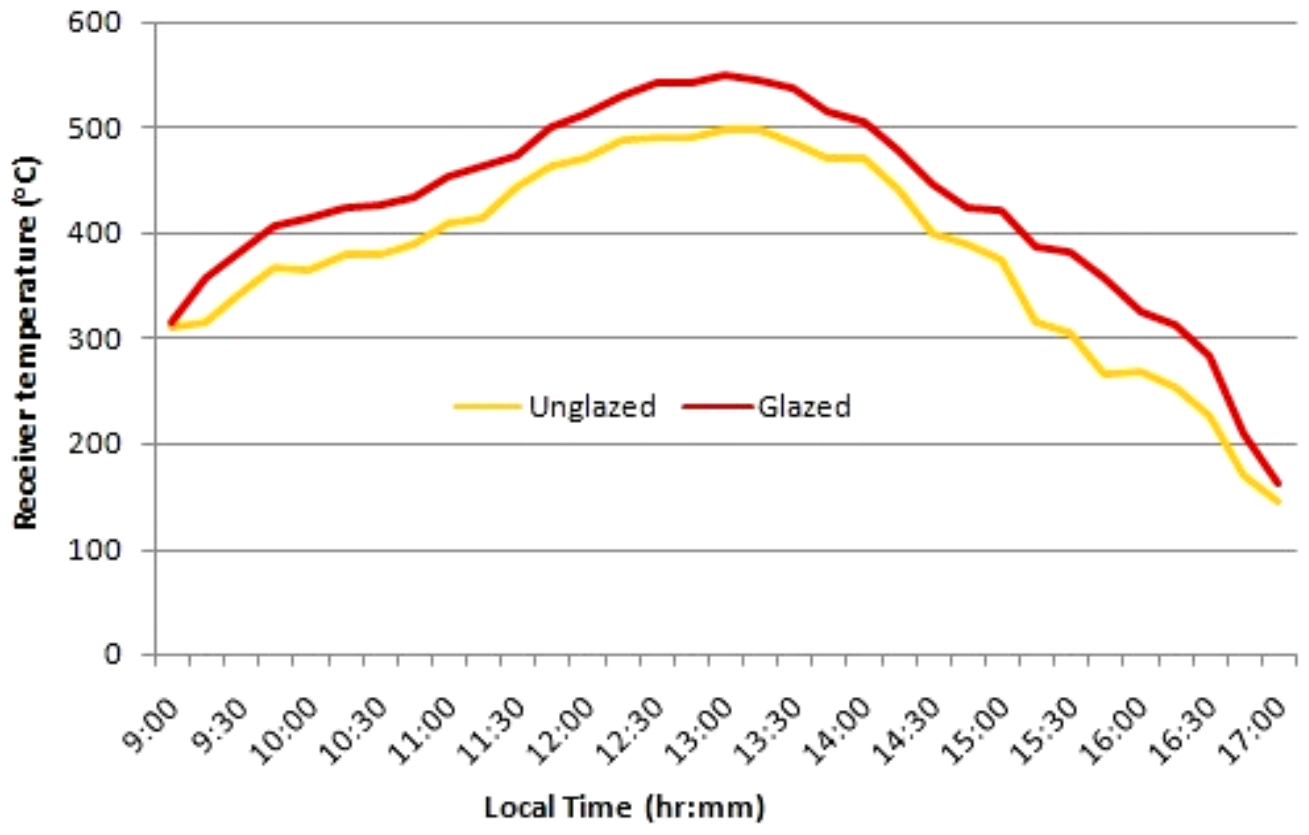

Figure 5. Receiver temperature variation

Comparative results of overall heat loss from the receiver in glazed and unglazed condition are presented in Figure 6. Radiant losses are significantly higher than convective losses due to higher temperature differences between the sky and receiver. Transparent glazing allows short wavelength reflected solar radiations to pass through it but does not allow passing emitted long-wavelength radiations from the receiver. Heat losses from the receiver are reduced due to the greenhouse effect. Convective loss from a glass-covered receiver is significantly reduced due to

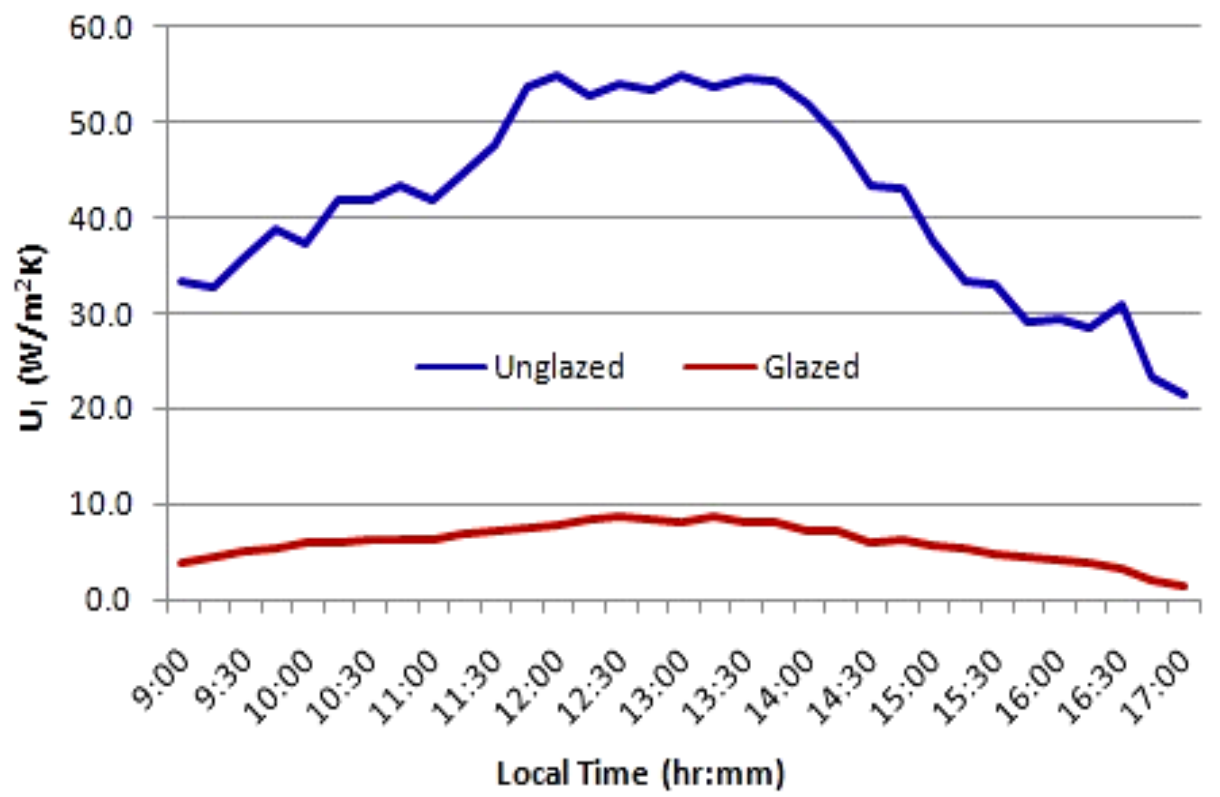

Figure 6. Overall heat loss coefficient variation 
the absence of forced air. The radiation heat transfer coefficient increases with an increase in receiver temperature result in higher reradiation heat loss from the unglazed receiver but in the case of the glazed receiver, only wind induce heat transfer coefficient cause convective heat loss through the glass cover. In unglazed condition, the overall heat loss coefficient varies between $21.55 \mathrm{~W} / \mathrm{m}^{2} \mathrm{~K}$ to $54.97 \mathrm{~W} / \mathrm{m}^{2} \mathrm{~K}$ whereas in the glazed condition it changes between $1.42 \mathrm{~W} / \mathrm{m}^{2} \mathrm{~K}$ to $8.77 \mathrm{~W} / \mathrm{m}^{2} \mathrm{~K}$.

From Figure 7, it is perceived that the percentage of useful heat available at the inner surface of the receiver depends on heat losses from the receiver. Heat losses are suppressed by providing glass cover on the receiver. Instability in the rate of energy transfer to the water in the receiver cavity is observed with the unglazed condition. Due to lower temperature difference between atmosphere and receiver less energy is transferred to water in a receiver cavity. With the use of glass cover on the receiver, radiant losses from receiver to atmosphere are significantly reduced during peak solar intensity. The average theoretical power available to water in a cavity of the glazed receiver is 5.51\% more than the unglazed condition. Power available for water in the cavity is calculated by considering only convective and radiative losses from the front surface of the receiver.

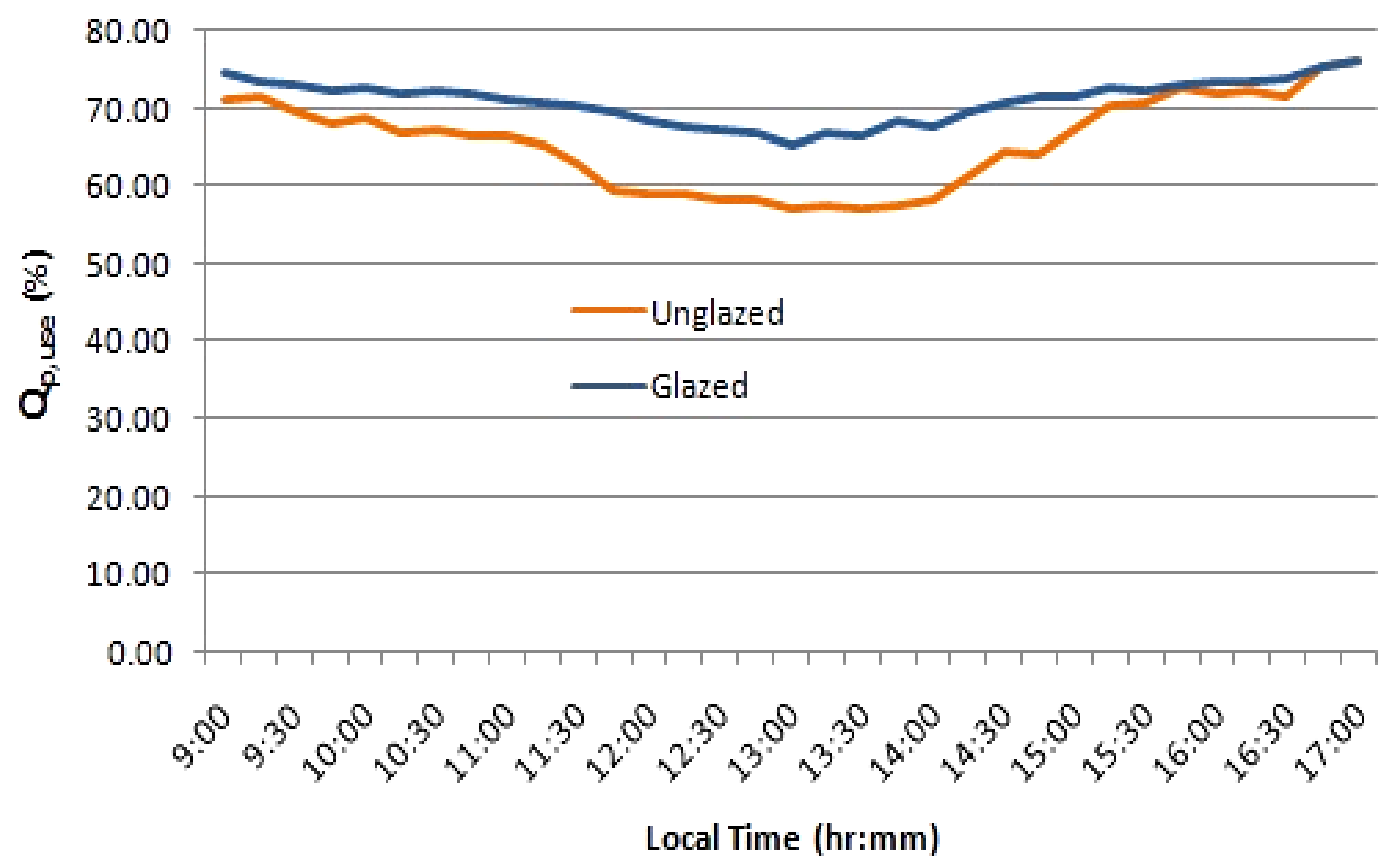

Figure 7. Variation in power transferred to water

Figure 8 reveals the time required for water in the tank and receiver to reach boiling point. Rate of change in water temperature in receiver up to $40^{\circ} \mathrm{C}$ is the same in glazed and unglazed condition, due to the high-temperature difference between receiver and water temperature. The temperature of circulating water through the glazed receiver increases linearly but for the unglazed receiver, small steps are observed in the temperature profile. Use of transparent glass cover on receiver reduces steam generation start time by 10-12 minutes due to enhanced heat transfer rate to water.

Figure 9 presents a comparison of the steam flow rate with the glazed and unglazed receiver. The maximum steam flow rate with the glazed receiver is found to be $5.2 \mathrm{~kg} / \mathrm{hr}$ at solar beam intensity $551 \mathrm{~W} / \mathrm{m}^{2}$ and $5.1 \mathrm{~kg} / \mathrm{hr}$ at solar beam intensity $708 \mathrm{~W} / \mathrm{m}^{2}$ with the unglazed receiver. In comparison with the unglazed receiver $6.6 \mathrm{~kg} / \mathrm{hr}$, the average increase in steam flow rate is observed even solar beam intensity reduced by $5.15 \%$, this is due to glazing only. It is found that the steam generation rate in the glazed condition is higher from the beginning to the end of experimentation. The steam generation rate rapidly decreases as solar beam intensity falls below $500 \mathrm{~W} / \mathrm{m}^{2}$. 


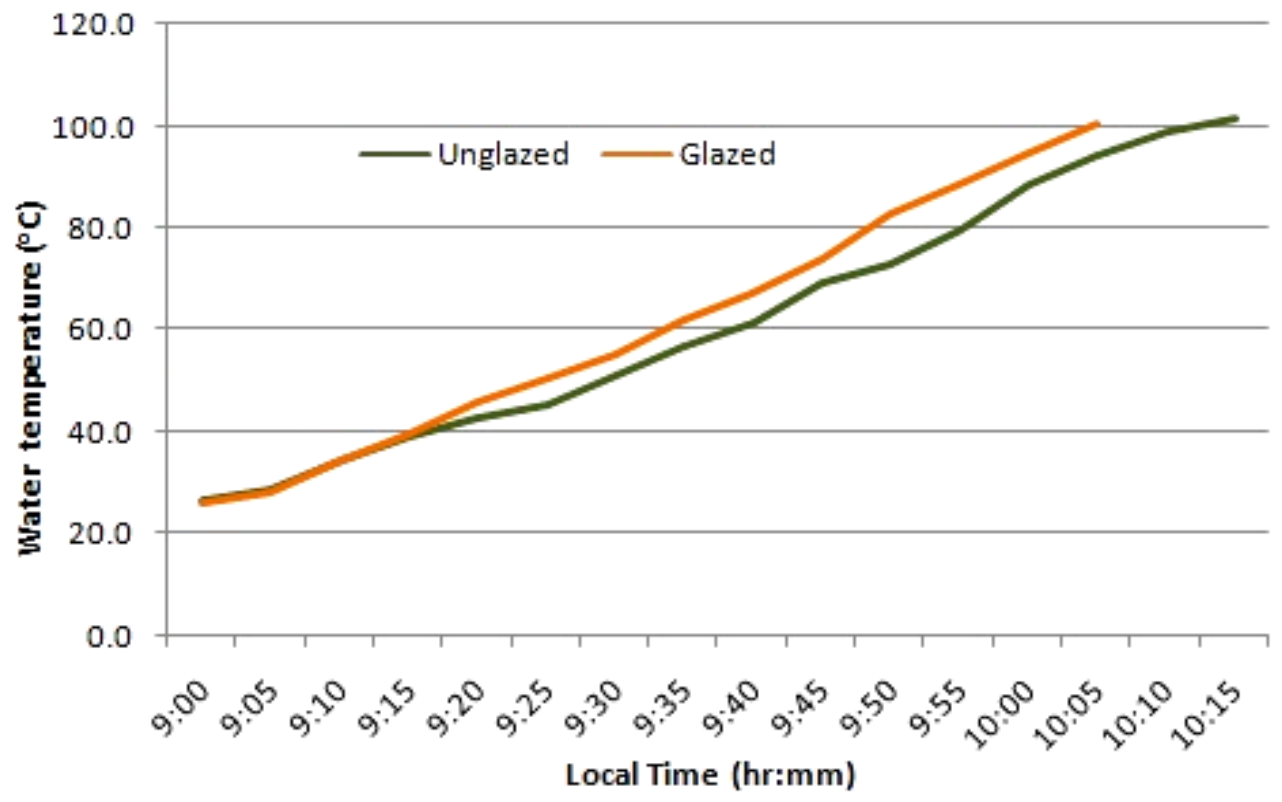

Figure 8. Water temperature variation

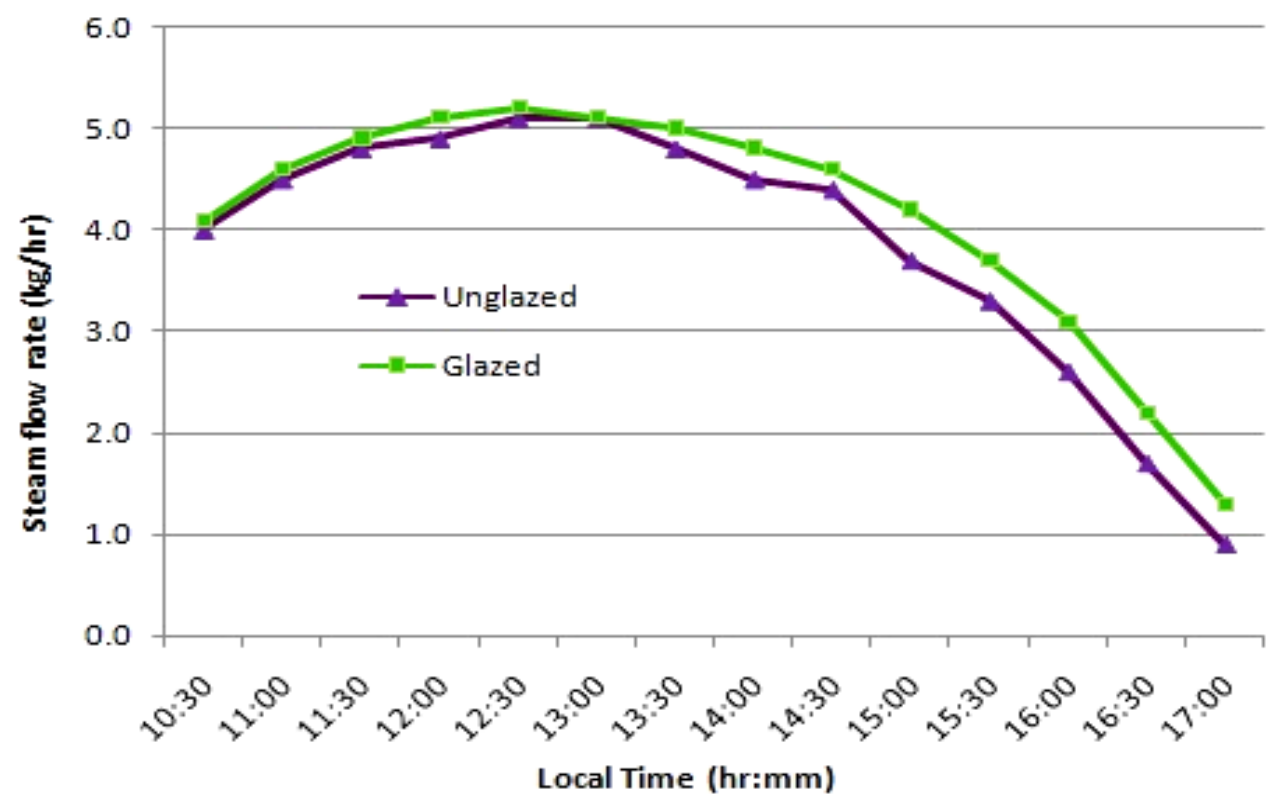

Figure 9. Steam flow rate variation

Figure 10 shows the efficiency of the system for direct steam generation. Efficiency rises with an increase in solar beam intensity and declines with a decrease in solar beam intensity. Highest efficiency achieved at 13:00 hr with glazing and without glazing. Variation in efficiency with a glazed receiver is small during peak solar beam intensity but fluctuations are observed with an unglazed receiver. The efficiency of Scheffler concentrator with the glazed receiver is high even at low solar beam intensity compared to the unglazed receiver. Glazing is highly beneficial for increasing efficiency above $50 \%$ for direct steam generation at atmospheric pressure. 


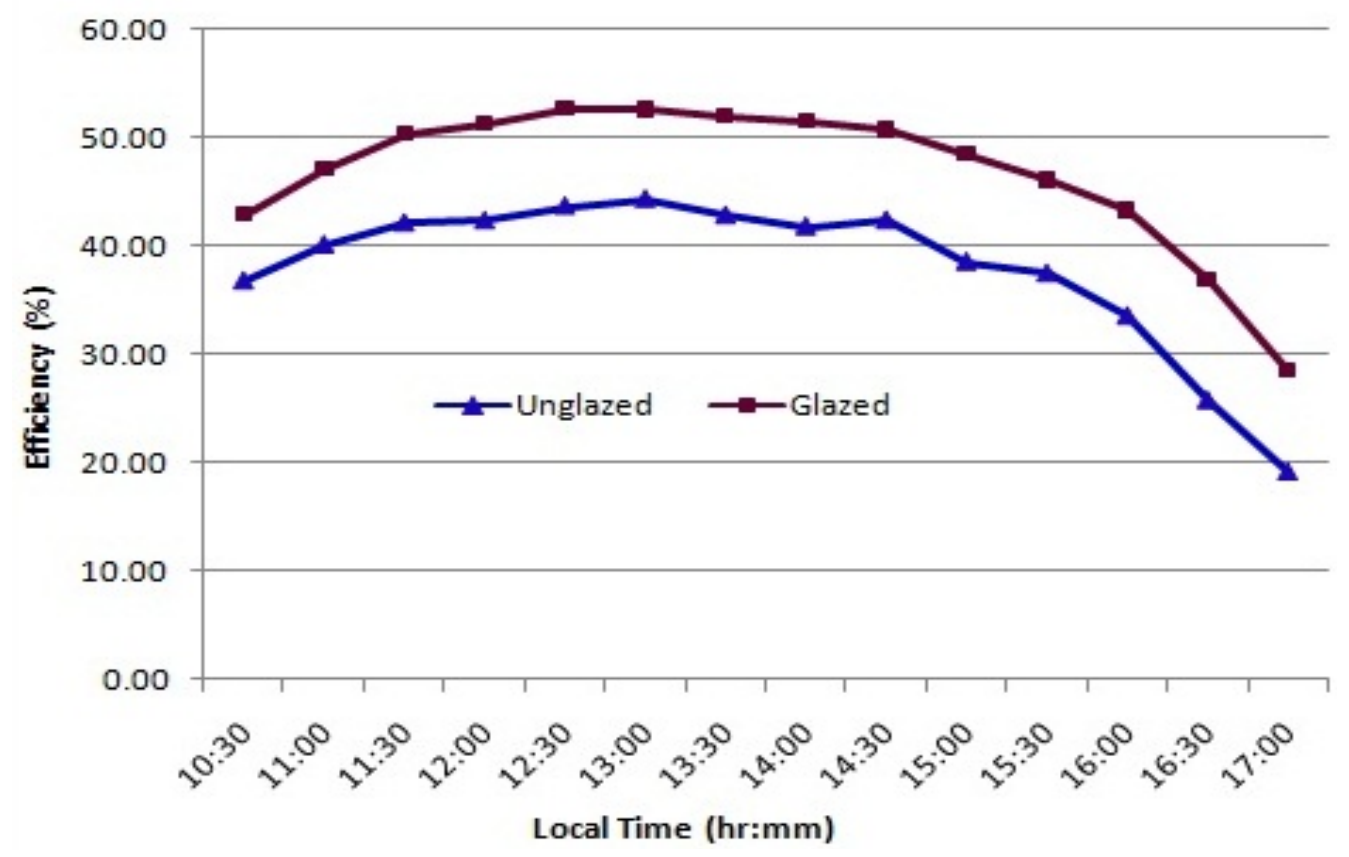

Figure 10. Efficiency variation for steam generation

\section{CONCLUSIONS}

Experimental results of the glazed and unglazed receiver of the Scheffler concentrator for direct steam generation have been concluded as follows:

- The average value of the overall heat loss coefficient without glazing is $41.8 \mathrm{~W} / \mathrm{m}^{2} \mathrm{~K}$ and with glazing, it is found as $6.04 \mathrm{~W} / \mathrm{m}^{2} \mathrm{~K}$. Enhancement in power transferred from the glazed receiver to the working fluid is $5.51 \%$.

- In the case of a glazed receiver, the average temperature at the focus is observed to be increased by $12.10 \%$ even solar beam intensity is lowered by $5.15 \%$, compared with an unglazed receiver.

- The time required to heat water in the circulation field of the receiver is lowered by 10-12 minutes.

- The average steam flow rate is observed to be $4.91 \mathrm{~kg} / \mathrm{hr}$ and $4.44 \mathrm{~kg} / \mathrm{hr}$ with glazed and unglazed receiver respectively, within the solar beam radiation range of $600-650 \mathrm{~W} / \mathrm{m}^{2}$.

- Transparent glass cover on the receiver increases the overall efficiency of the system by $8.74 \%$ when compared with the unglazed.

The use of transparent glazing over the receiver of Scheffler reflector is recommended to reduce the losses from the receiver to the atmosphere and enhance the performance of the parabolic dish type concentrator.

\section{NOMENCLATURE}

$I_{b} \quad$ Solar beam radiation, $\mathrm{W} / \mathrm{m}^{2}$

$A_{c} \quad$ Aperture area of concentrator, $\mathrm{m}^{2}$

$A_{s} \quad$ Surface area of concentrator, $\mathrm{m}^{2}$

$Q_{r} \quad$ Power received by receiver, $\mathrm{W}$

$Q_{c} \quad$ Power received by concentrator, $\mathrm{W}$

$Q_{l} \quad$ Heat loss, W

$Q_{u} \quad$ Useful heat, W

$Q_{\text {con }} \quad$ Convective heat loss, W

$Q_{\text {rad }} \quad$ Radiative heat loss, W

$T \quad$ Temperature, ${ }^{\circ} \mathrm{C},{ }^{\circ} \mathrm{K}$

$k \quad$ Thermal conductivity, $\mathrm{W} / \mathrm{m}^{\circ} \mathrm{C}$ 


$\begin{array}{ll}h_{\text {con }} & \text { Convective heat transfer coefficient, W/m } \mathrm{m}^{20} \mathrm{~K} \\ h_{\text {rad }} & \text { Radiative heat transfer coefficient, W/m } \mathrm{m}^{20} \mathrm{~K} \\ U_{l} & \text { Overall heat loss coefficient } \\ N u & \text { Nusselt number } \\ P r & \text { Prandtl number } \\ R a & \text { Rayleigh number } \\ L & \text { Cavity length, } \mathrm{m} \\ V & \text { wind speed, } \mathrm{m} / \mathrm{s} \\ \eta & \text { Energy efficiency, \% } \\ \text { Greek symbols } & \\ \delta & \text { Declination angle, degree } \\ \tau & \text { Transmitivity of glass cover } \\ \rho & \text { Reflectance of concentrator reflecting surface } \\ \varepsilon & \text { Emissivity } \\ \sigma & \text { Stefan-Boltzmann constant } \\ \text { Subscripts } & \\ \text { un } & \text { Unglazed } \\ \text { gl } & \text { Glazed } \\ \mathrm{r} & \text { Receiver } \\ \text { a } & \text { Ambient } \\ \text { g } & \text { Glass cover } \\ \text { Abbreviation } & \\ \text { DNI } & \text { Direct Normal Irradiance, W/m } \\ & \end{array}$

\section{REFERENCES}

[1] Naik H, Baredar P, Kumar A. Medium temperature application of concentrated solar thermal technology: Indian perspective. Renew Sustain Energy Rev 2017;76:369-78. https://doi.org/10.1016/j.rser.2017.03.014.

[2] Salgado Conrado L, Rodriguez-Pulido A, Calderón G. Thermal performance of parabolic trough solar collectors. Renew Sustain Energy Rev 2016;67:1345-59. https://doi.org/10.1016/j.rser.2016.09.071.

[3] Gudekar AS, Jadhav AS, Panse S V, Joshi JB, Pandit AB. Cost effective design of compound parabolic collector for steam generation. Sol Energy 2013;90:43-50. https://doi.org/10.1016/j.solener.2012.12.020.

[4] Hussein AK, Li D, Kolsi L, Kata S, Sahoo B. A Review of Nano Fluid Role to Improve the Performance of the Heat Pipe Solar Collectors. Energy Procedia 2017;109:417-24. https://doi.org/10.1016/j.egypro.2017.03.044.

[5] Hussein AK. Applications of nanotechnology in renewable energies - A comprehensive overview and understanding. Renew Sustain Energy Rev 2015;42:460-76. https://doi.org/10.1016/j.rser.2014.10.027.

[6] Hussein AK. Applications of nanotechnology to improve the performance of solar collectors - Recent advances and overview. Renew Sustain Energy Rev 2016;62:767-92. https://doi.org/10.1016/j.rser.2016.04.050.

[7] Tian M, Su Y, Zheng H, Pei G, Li G, Riffat S. A review on the recent research progress in the compound parabolic concentrator (CPC) for solar energy applications. Renew Sustain Energy Rev 2018;82:1272-96. https://doi.org/10.1016/j.rser.2017.09.050.

[8] Fuqiang W, Jianyu T, Lanxin M, Chengchao W. Effects of glass cover on heat flux distribution for tube receiver with parabolic trough collector system. Energy Convers Manag 2015;90:47-52. https://doi.org/10.1016/j.enconman.2014.11.004.

[9] Panchal H, Patel J, Parmar K, Patel M. Different applications of Scheffler reflector for renewable energy: a comprehensive review. Int J Ambient Energy 2018:10.1080/01430750.2018.1472655. https://doi.org/10.1080/01430750.2018.1472655.

[10] Ruelas J, Palomares J, Pando G. Absorber design for a Scheffler-Type Solar Concentrator. Appl Energy 2015;154:35-9. https://doi.org/10.1016/j.apenergy.2015.04.107.

[11] Loni R, Kasaeian AB, Asli-Ardeh EA, Ghobadian B, Najafi G. Comparison study of air and thermal oil application in a solar cavity receiver. J Therm Eng 2019;5:221-9. https://doi.org/10.18186/thermal.654628. 
[12] Loni R, Kasaeian A, Asli-Ardeh EA, Ghobadian B, Najafi G. Thermal evaluation of cavity receiver using water/Pg as the solar working fluid. J Therm Eng 2019;5:446-55. https://doi.org/10.18186/thermal.624341.

[13] Trushevskii SN, Mitina I V. Vacuum glazing units and solar collectors. Appl Sol Energy 2008;44:172-5. https://doi.org/10.3103/s0003701x08030079.

[14] Bisen A, Dass PP, Jain R. Parametric Studies of Top Heat Loss Coefficient of Double Glazed Flat Plate Solar Collectors. MIT Int J Mech Eng 2011;1:71-8.

[15] Dafle VR, Shinde NN. Design, Development \& Performance Evaluation Of Concentrating Monoaxial Scheffler Technology For Water Heating And Low Temperature Industrial Steam Application. Int J Eng Res Appl 2012;2:848-52.

[16] Uhlig R, Flesch R, Gobereit B, Giuliano S, Liedke P. Strategies enhancing efficiency of cavity receivers. Energy Procedia 2013;49:538-50. https://doi.org/10.1016/j.egypro.2014.03.058.

[17] Jadhav AS, Gudekar AS, Patil RG, Kale DM, Panse S V. Performance analysis of a novel and cost effective CPC system. Energy Convers Manag 2013;66:56-65.

[18] Mbodji N, Hajji A. Performance Testing of a Parabolic Solar Concentrator for Solar Cooking. J Sol Energy Eng Trans ASME 2016;138. https://doi.org/10.1115/1.4033501.

[19] Chandrashekara M, Yadav A. Experimental study of exfoliated graphite solar thermal coating on a receiver with a Scheffler dish and latent heat storage for desalination. Sol Energy 2017;151:129-45. https://doi.org/10.1016/j.solener.2017.05.027.

[20] Chandrashekara M, Yadav A. An experimental study of the effect of exfoliated graphite solar coating with a sensible heat storage and Scheffler dish for desalination. Appl Therm Eng 2017;123:111-22. https://doi.org/10.1016/j.applthermaleng.2017.05.058.

[21] Abedini Najafabadi H, Ozalp N. Aperture size adjustment using model based adaptive control strategy to regulate temperature in a solar receiver. Sol Energy 2018;159:20-36. https://doi.org/10.1016/j.solener.2017.10.070.

[22] Stefanovic VP, Pavlovic SR, Bellos E, Tzivanidis C. A detailed parametric analysis of a solar dish collector. Sustain Energy Technol Assessments 2018;25:99-110. https://doi.org/10.1016/j.seta.2017.12.005.

[23] Nene AA, Ramachandran S, Suyambazhahan S. Effect of Wind Flow on Convective Heat Losses from Scheffler Solar Concentrator Receivers. J Inst Eng Ser C 2018. https://doi.org/10.1007/s40032-018-0463-5.

[24] Renuka M, Balaji K, Sakthivadivel D, Meikandan M, Ganesh Kumar P. Selection of optimal glazing material for solar thermal applications using grey relational analysis. Int J Ambient Energy 2019;0:1-13. https://doi.org/10.1080/01430750.2018.1563820.

[25] Li D, Li Z, Zheng Y, Liu C, Hussein AK, Liu X. Thermal performance of a PCM-filled double-glazing unit with different thermophysical parameters of PCM. Sol Energy 2016;133:207-20. https://doi.org/10.1016/j.solener.2016.03.039.

[26] Hussein, Ahmed Kadhim A AW. Applications Of Nanotechnology To Enhance The Performance of The Direct Absorption Solar Collectors. J Therm Eng 2016;2:529-40.

[27] Kumar A, Shukla SK. Experimental and numerical analysis of a helical coil solar cavity receiver: Thermal oil as the heat transfer fluid. Int J Green Energy 2019;16:716-32. https://doi.org/10.1080/15435075.2019.1619566.

[28] Bopche SB, Kumar S. Experimental investigations on thermal performance characteristics of a solar cavity receiver. Int J Energy Environ Eng 2019;10:463-81. https://doi.org/10.1007/s40095-019-00321-4.

[29] López O, Baños A, Arenas A. On the thermal performance of flat and cavity receivers for a parabolic dish concentrator and low/medium temperatures. Sol Energy 2020;199:911-23. https://doi.org/10.1016/j.solener.2019.07.056.

[30] MNRE. Scheffler Dish based Solar System: Operations and Maintenance Manual. 2014.

[31] Michaelides IM, Lee WC, Wilson DR, Votsis PP. Computer simulation of the performance of a thermosyphon solar water-heater. Appl Energy 1992;41:149-63. https://doi.org/10.1016/03062619(92)90042-A.

[32] Fang Y, Arya F. Evacuated glazing with tempered glass. Sol Energy 2019;183:240-7. 
https://doi.org/10.1016/j.solener.2019.03.021.

[33] Munir A, Hensel O, Scheffler W. Design principle and calculations of a Scheffler fixed focus concentrator for medium temperature applications. Sol 2010;84:1490-502. https://doi.org/10.1016/j.solener.2010.05.011.

[34] Duffie JA, Beckman WA. Solar Engineering of Thermal Processes. Fourth edi. Hoboken, New Jersey: John Wiley \& Sons; 2013.

[35] Frank P. Incropera, David P. Dewitt, Theodore L. Bergman ASL. Fundamentals of Heat and Mass Transfer. John Wiley \& Sons, Inc; 2007.

[36] Oosthuizen PH, Kalendar AY. Natural convective heat transfer from short inclined cylinders. 2014. https://doi.org/10.1007/978-3-319-02459-2.

[37] J. P. Holman. Heat Transfer. sixth. McGraw-Hill; 1986.

[38] Kumar S, Mullick SC. Glass cover temperature and top heat loss coefficient of a single glazed flat plate collector with nearly vertical configuration. Ain Shams Eng J 2012;3:299-304. https://doi.org/10.1016/j.asej.2012.03.008.

[39] R. J. Moffat. Describing the uncertainties in experimental results. Exp Therm Fluid Sci 1988:3-17. 